\title{
Technological equipment management for 3D additive printing of building nanocomposites
}

\author{
O.V. Ivanova (D), R.M. Khalikov* iD, A.S. Salov, M.Kh. Nizamutdinov, V.V. Zinnatullin \\ Ufa State Petroleum Technological University, Ufa, Bashkortostan Republic, Russia \\ * Corresponding author: e-mail: rauf_khalikov@mail.ru
}

\begin{abstract}
Introduction. The development of innovative approaches to digital equipment control that ensure the production of 3D building structures with high operational and technical-economic characteristics remains an urgent task. The handling and maintenance of technological equipment during the process of 3D-printing of construction objects do not always meet the modern requirements of technical systems management. Methods and materials. 3D-printing is based on the method of extrusion: molding of a building structure layer-by-layer with the addition and fairly rapid subsequent solidification of nanocomposite building materials. The resulting optimized nanocomposition must have the required rheology, which set the comb-like polycarboxylate esters with nanosteric repulsion at a distance of $\approx 11 \mathrm{~nm}$. In order to organize a stable 3D-printing technology, it is also necessary to select the appropriate optimal fillers that provide the necessary physical, mechanical and operational characteristics to the hardened nanocomposite. Results. The effectiveness of three-dimensional printing calls for the coordinated operation of a construction-grade 3D-printer. In this regard, it is necessary to have concrete pumping equipment that is able to pump the initial nanocomposition through flexible pipelines at a certain speed. It is necessary to consider the influence of pressure and volume to increase the power of the concrete pump motor by $14-17 \%$, and at the same tine reduce the level of vibrations. Discussion. Digital 3D-technologies reveal unique opportunities for innovative production of three-dimensional construction objects and engineering structures. Technological quality management of 3D-printing depends on the correct alignment of the printer mechanisms, and the reduction of defective products can be achieved by adjusting the molding parameters of building nanocomposites. The structure-forming curing of Portland cement nanocomposites is based on the formation of fractal structures of calcium hydrosilicate clusters with dimensions of $47-51 \mathrm{~nm}$, that form nanoaggregates (125-132 nm), which gradually cement the fillers due to adhesive interactions. The high demand for the corresponding equipment only strengthens the advantages of 3D-additive technologies: its practical waste-free operation, low power consumption of 3D-printers, time reduction of design-to-completion process by $8-11$ times. Conclusions. Technological managing of concrete pump equipment for 3D-additive printing of building nanocomposites reduces energy costs by $26-29 \%$, and at the same time reduces the level of vibration.
\end{abstract}

KEYWORDS: additive nanotechnology, 3D-printer, digital construction, concrete pumps, 3D-printing of nanocompositions, quality management.

FOR CITATION: Ivanova O.V., Khalikov R.M., Salov A.S., Nizamutdinov M.Kh., Zinnatullin V.V. Technological equipment management for 3D additive printing of building nanocomposites. Nanotechnologies in Construction. 2021; 13(2): 117-123. Available from: doi: 10.15828/2075-8545-2021-13-2-117-123.

\section{INTRODUCTION}

I ntensive work on creating breakthrough trends in the construction industry and high-tech equipment for 3D-additive technologies [1-3] as rapid prototyping tools continues in many countries. The operation and maintenance of technological and transport equipment in the course of 3D-printing of construction infrastructure does not fully meet modern requirements, there is no national standard for additive manufacturing. Therefore, the engineering of innovative approaches to equipment management that reliably ensures the production of threedimensional building structures with increased technical and economic characteristics remains an urgent task.

In recent years, innovative approaches have appeared, for example, three-dimensional technologies for "printing" individual structures, buildings in the construction industry using fibers, which removes the need for traditional formwork. 3D-additive technologies are one of the most dynamically developing areas of autonomous

(c) Ivanova O.V., Khalikov R.M., Salov A.S., Nizamutdinov M.Kh., Zinnatullin V.V., 2021 
"digital" production [4] and high-quality management of technical systems makes it possible to design a variety of architectural forms of construction.

The purpose of this article is to study the use of technological and transport equipment for 3D-printing of infrastructure buildings in the construction industry.

\section{METHODS AND MATERIALS}

3D-additive printing is based on the method of extrusion: molding of a building structure layer-by-layer by successive addition and subsequent curing of nanocomposite building materials. To ensure the appropriate pumping volume, the formed optimized homogeneous cement (less often modified gypsum) nanocomposition with mineral fillers must have the required rheology, the optimal plasticity limit is $1.0-2.5 \mathrm{kPa}$. Portland cement nanobinders allow for more selective control of the variation dynamics in strength and rheological characteristics, changes in durability during the operation of building structures. To control the rheological behavior of building nanocompositions in the process of 3D-printing, the effective technological characteristics of superplasticizers include comb-like polycarboxylate esters with nanosteric repulsion at a distance of $\approx 11 \mathrm{~nm}[5]$.

The print head of a $3 \mathrm{D}$-printer is a nozzle from which a raw nanocomposition is squeezed out (extruded). The trajectory of the nozzle is determined by a digital CADprogram: after the complete application of one layer is completed, the working platform is moved down or up by the thickness of one layer, and other layers are "printed". With this technology, a special role is given to the speed of "printing", which should be optimal: that is, allow previously "printed" layers of the nanocomposite material to gain initial strength to ensure appropriate adhesion between the individual layers.

Construction of 3D-printing includes the stages of preparing a viscoplastic nanocomposite mixture, transporting it from the mixer via flexible pipelines to the extruder, extruding it with a 3D-printer nozzle, and hardening the printed layers of nanomaterial. Another significant feature of the additive technology method is the programming of the speed characteristics for feeding and laying the initial nanocomposition, taking into account the geometric dimensions $(5-20 \mathrm{~cm})$ of the printing nozzle (fig. 1).

It should be noted that in order to ensure a stable technology for layer-by-layer 3D-printing, the raw nanomaterial composition must have a high yield strength. Effective control of the rheology of nanocompositions in the course of 3D-printing is possible with the combined use of nanodisperse multidirectional viscosity modifiers, mechanical activation, and similar methods [6, 7]. Dynamic structure formation in multiphase (multicomponent) 3D-printing nanocompositions occurs due to the interaction of col-

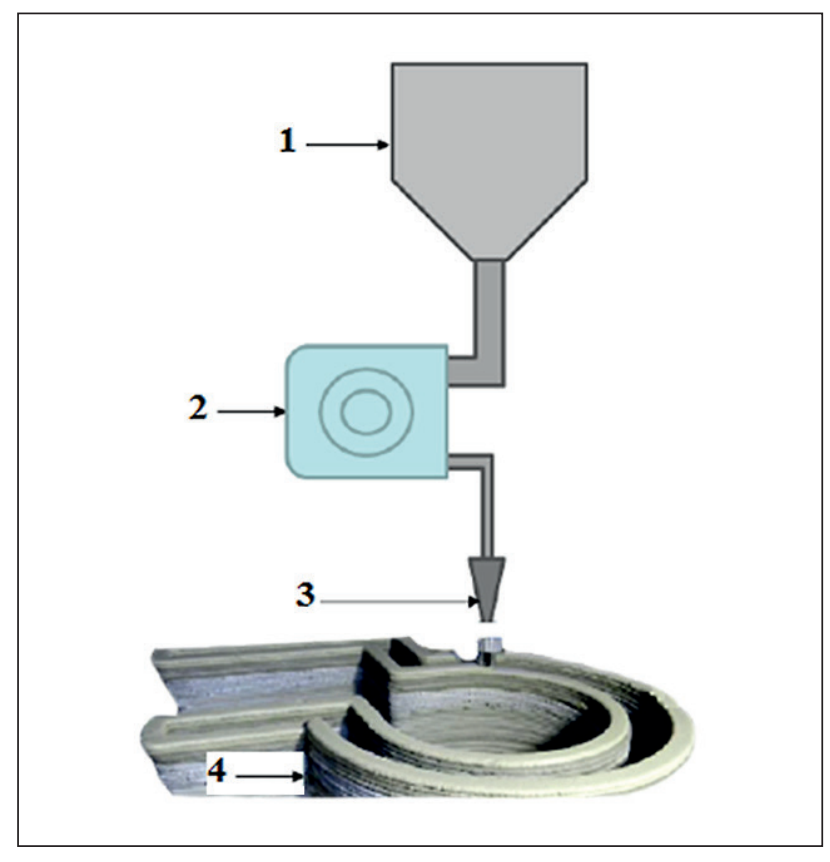

Fig. 1. Traditional scheme of layer-by-layer extrusion of nanocomposition in 3D-additive technology:

1- raw material container; 2 - concrete pump; $3-3 \mathrm{D}$-printer nozzle; 4 - building construction

loidal binders, nanosuspension of microfillers, etc. The method of fractal analysis of the structure-forming processes of nanocomposites allows us to clearly track the kinetics of hardening: as a result of polycondensation, multi-fractal aggregates of nanobinders are formed during rough adhesion of colloidal microparticles.

The nanobinding composition in 3D-printing technology should be "laid" in even layers and at the same time stay in one place, i.e. be quite rigid. At the same time, the nanobinders design faces the technological challenge of reducing the setting time: not to "clog" the nozzle of the 3D-printer, and also to "have time" to form an adhesion with the previous layer. The layer height of $2-3 \mathrm{~cm}$ is selected experimentally: when laying a new layer, the previous layers must have sufficient strength: 1.5-2 MPa when compressed in the cured state. Thixotropic agents (for example, bentonite) affect the processability of construction 3D-printing through modification of the hardening kinetics.

A technology is proposed [8], when in the process of extrusion of the initial nanocomposition, spatulas (mounted on the feed nozzle) align the surface of $3 \mathrm{D}$-printing. It should be noted that in this case, a thixotropic nanocomposition of $3 \mathrm{D}$-additive technologies is selected, i.e. under physical and mechanical influence, the viscosity decreases sharply, which is restored quite quickly in a few minutes.

The problem of control and regulation of the optimal characteristics of nanocompositions for $3 \mathrm{D}$-printing is 
also solved by the introduction of multidirectionally acting chemical nanoadditives. For example, in the article [9], a composition was selected for 3D-printing: cement, sand (size $2 \mathrm{~mm}$ ), microsilica and $1 \%$ polycarboxylate superplasticizer. The hardening was slowed down (regulated) by nanoadditives of $0.5 \%$ citric and nitrotrimethylphosphonic acids, and aluminum salts in an acidic medium were used as a setting catalyst [10]. In addition, the raw nanocomposition was reinforced with a polypropylene fiber with a length of $12 \mathrm{~mm}$ to reduce deformation.

\section{RESULTS}

The efficiency of three-dimensional printing provides for the coordinated functioning of the construction 3Dprinter and the pumping of raw nanocomponents. In this regard, it is necessary to have pumping (screw, piston, centrifugal) equipment capable of pumping and feeding the initial nanocomposition with a certain discharge speed and geometric accuracy, which is provided by a robotic system for automatically moving the nozzle (injector) of the 3D-printer head.

The most important requirement for concrete pumping equipment in the process of $3 \mathrm{D}$-printing is the ability to pump nanocomposite mortar horizontally and (or) vertically for tens of meters through flexible pipes. In accordance with the requirements of the technological regime in $3 \mathrm{D}$-additive technologies, the main function of the electric drive is to ensure the stable operation of the concrete pump [11-14]. When choosing the power of electric motors for concrete pumps in the process of 3D-printing, working with a variable load: the maximum pressure is Pmax at the outlet of the pump pumping the nanocomposition and the volume of the nanocomposite mixture is $\mathrm{V}$ (fig. 2), the power of electric drives is overestimated taking into account the heaviest starts.

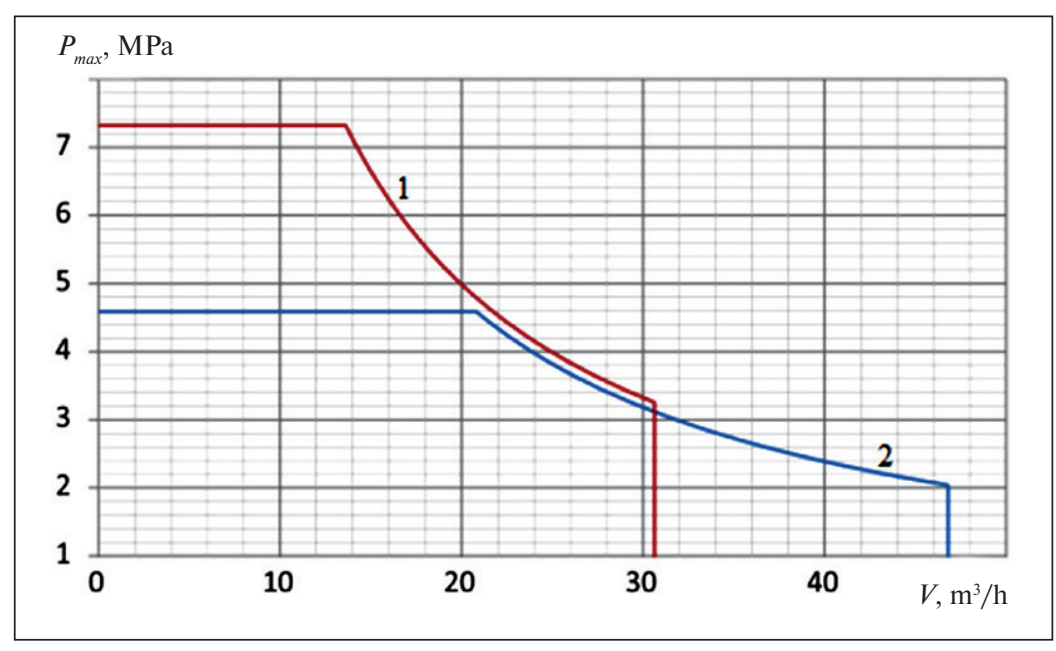

Fig. 2. Controlled dynamics of the 3D-printer concrete pump efficiency in the mode of: 1 - high pressure; 2 - maximum pumped volume

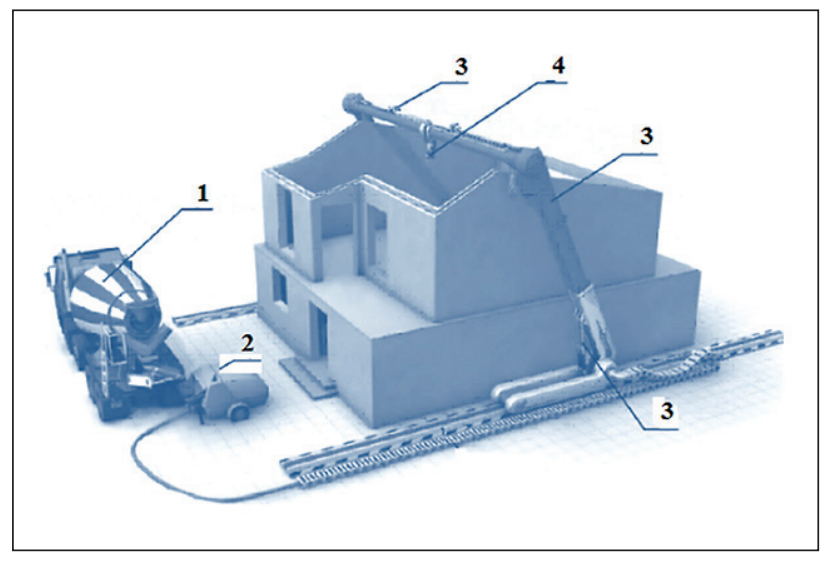

Fig. 3. Portal 3D-printer for "printing" low-rise buildings: 1 - concrete mixer truck with nanocomposite raw materials; 2 - electric pump; 3 - movement mechanisms; 4 - extruder nozzle

It should be noted that the maximum values of the pressure Pmax and the volume of the pumped nanocomposition $\mathrm{V}$ cannot be achieved simultaneously. The effective power of the electric drive at the nominal operating mode of the concrete pump varies from $320 \mathrm{~kW}$ to $470 \mathrm{~kW}$. Taking into account the influence of limiting factors allows for increase in power of the concrete pump motor by $14-17 \%$, reduces energy costs by $26-29 \%$, and simultaneously reduces the level of vibration. When using an asynchronous electric motor between it and the concrete pump, it is necessary to install a mechanical transmission, which reduces the reliability of the electric drive, increases its weight and increases vibrations; the problem is solved by using electric motors that have a low angular speed of the shaft: wave electric drives and motors with a rolling rotor.

In industrial conditions, employees of the Ufa State Petroleum Technical University built a one-story smallsized pavilion using the AMT S1160 pilot 3D-printer. Automated devices of portal 3D printers, which operate in angular coordinates and are driven by electric drives, are the most economical due to the control of reliability in the construction of low-rise buildings and building structures (fig. 3).

Technological managing of the 3Dprinting concrete pump is carried out automatically by electronic equipment; additionally, all functions can be easily maintained manually, which allows the concrete pump to continue working if the control unit or sensors fail. It should be noted that before the concrete pump is fully powered, a starting mixture or a cement "milk" should be used: a mobile mixture of cement and water. The 
autonomous water washing system in 3D-additive technologies allows to quickly clean the tubes (flexible hoses), the drum mixer of concrete mixers from the adhering residues of construction nanosolvent. Therefore, for reliable managing of high-quality operation of technological equipment in the process of 3D-printing, appropriate water treatment is necessary (at low temperatures - clean warm water) $[15,16]$.

\section{DISCUSSION}

Digital 3D-additive technologies reveal unique opportunities for the production of three-dimensional construction objects and engineering structures, which are in high demand in the XXI century. Technical disadvantages of additive technologies such as vertical surface irregularities or the appearance of microcracks due to uneven shrinkage are gradually minimized. The popular developments of the corresponding equipment only strengthen the advantages of 3D-additive technologies: practical waste-free operation; low power consumption and noiselessness of 3D-printers; reduction of the time from design to completion by $8-11$ times. The quality of 3D-printing depends on the correct alignment of the printer mechanisms, and the reduction of defective products (construction objects) can be achieved by adjusting the molding parameters. Due to the intelligent algorithms of the optimized CAD-program, it is possible to reduce the number of test passes of the 3D-printer.

The solidification time of nanoconcrete compositions in the process of 3D-printing can be up to several hours, so to increase the speed, it is necessary to dry the printed layers. One of the promising solution to this disadvantage is the addition of technogenic waste to concrete nanocompositions [17], for example, the reuse of building materials [18]. By reducing the cost of $3 \mathrm{D}$-additive technologies in the future, within the framework of the life cycle concept, it is possible to accelerate the design, construction of three-dimensional buildings and reconstruction.

It should also be noted that the operation of most $3 \mathrm{D}$-printers is carried out in the formless molding of building structures. The addition of $2-3 \%$ of the sodium silicate production waste into the composition of nanocompositions during 3D-additive printing makes it possible to accelerate the setting and at the same time increase the strength characteristics. In the process of 3D-printing of structures with a high coefficient of reinforcement (steel fibers, basalt, glass, carbon fibers), it is technologically important to be able to place the building nanocompositions with ease.

The development of 3D-additive technologies requires an integrated approach to the study of building nanomaterials under operating conditions, especially taking into account changes in the human environment in specific conditions. New challenges of increased environmental pressures require new solutions to optimize the following interaction: "human $\leftrightarrow$ nanomaterial $\leftrightarrow$ habitat". Therefore, the development of the basic foundation for the creation, production, operation, disasembling and reuse of a new generation of "green" nanocomposites is an important interdisciplinary task.

The improvement of trouble-free and reliable management and good performance of a construction 3D-printer can be carried out at the expense of unloaded redundancy [19]. The electronic control unit for positioning the nozzle of the extruder, the monitoring cameras for the 3D-printing process [20] allow to control the design stages of construction objects. One of the promising technologies for producing nanodispersions from secondary concrete is the cavitation grinding technology $[21,22]$ : when the rotor rotates in the working chamber of the pump, high-frequency acoustic vibrations occur, accompanied by cavitation and hydrodynamic phenomena, under the action of which nanoparticles of building materials are crushed.

Sensors that allow synchronous monitoring of the structure-forming processes of nanocomposites enable optimal hardening of the "printed" layers of 3D-additive printing of building constructions. The structure-forming curing of Portland cement nanocomposites is based on the formation of fractal structures of clusters of calcium hydrosilicates with dimensions of $47-51 \mathrm{~nm}$, forming nanoaggregates $(125-132 \mathrm{~nm})$ [23] with a rough surface of nanocomposites, which, due to adhesive interactions, gradually cement fillers. Technological manage of concrete pumping equipment [24] for 3D-additive printing of building nanocomposites allows for high resistance to mechanical influences on side fences [25].

Optimal quality management [26] of the entire technological process for 3D-printing of construction objects based on nanocomposites involves taking into account the quality indicators of building materials, buildings and structures, engineering equipment, etc. The quality indicators of nanocomposite raw materials contained in the standards, such as durability, recoverability, transportability, as well as the condition of buildings, structures and their elements, engineering equipment, tooling and tools (defect-free state, reliability and safety), do not fully cover the problem of quality management. This problem can be solved by the introduction of the quality management system standard GOST R ISO 9001-2015 at construction enterprises, which involves establishing feedback from consumers.

The design of the quality management process structure [27] in accordance with the requirements of the ISO 9001 standard reflects the need to form a system of responsibility for $3 \mathrm{D}$-additive printing. The monitoring mechanism, as well as corrective and preventive measures for the compliance of the production of three- 
dimensional structures and the quality of products with established external and internal requirements, implements assessments for goals in the field of technological equipment management.

The operation and maintenance of technological equipment in the course of 3D-printing of construction infrastructure requires the appropriate organization of certification and licensing of transport systems [28]. Currently, technological management of 3D-additive printing equipment for building nanocomposites is possible at the stage involving concrete mixers for the delivery of concrete nanomixtures.

The quality of applied concrete in the process of 3D-printing of building nanocomposites depends largely on the cost-effective transportation of the finished nanocrete mixture prepared at the plant. The use of a concrete mixer truck makes it possible to increase the productivity of 3D-additive technology and optimize the costs of preparing and delivering concrete $[29,30]$. Concrete mixers can also be used to deliver metered components of a concrete nanomixture, prepare it en route or upon arrival at a construction site for $3 \mathrm{D}$-additive printing.

The concrete mixer truck is a rotating drum mounted on the frame of an automobile chassis, and inside the drum there are two spiral blades, during the rotation of which the components of the nanoconcrete mixture are maintained in a thixotropic state. A characteristic feature of the concrete mixer truck with mixers is a constant angle of inclination from 10 to 15 degrees of the container for mixing cement-sand nanosolution. The closed rotating drum preserves the uniformity of the 3D-additive printing concrete nanomixture and protects it from external negative factors, thereby maintaining the necessary performance characteristics of the nanocomposition during transportation.

Currently, in the process of 3D-printing, concrete mixers with hydraulic drives are used, which are much lighter compared to a mechanical transmission, and also has the ability to continuously adjust the drum speed in the range of $0-20$ revolutions per minute. The hydraulic pump of the hydraulic drive is driven by a diesel engine of the concrete mixer truck or a separate engine, and the control device [31] allows to set the speed of rotation of the diesel engine depending on the rotation speed of the mixing drum. Concrete mixers with a mixer from Russian manufacturers are represented by models that are equipped with an individual power plant, an autonomous drum with a volume of up to $12 \mathrm{~m}^{3}$.

The reasonably calculated cost of delivery of concrete nanomixtures in the course of 3D-additive printing makes it possible to quickly select concrete mixers of the appropriate size, depending on the distance of nanocomposites transportation, the volume of the drum capacity, technical characteristics and working conditions (temperature fluctuations from -20 to $+40^{\circ} \mathrm{C}$ ). The best option for transporting the nanoconcrete mixture at distances from 4 to $6 \mathrm{~km}$ are concrete mixers with a volume of $6-8 \mathrm{~m}^{3}$.

In the market of concrete mixers of the Russian Federation, about $70 \%$ is the share of "Tuymazinsky Plant of concrete trucks" (Republic of Bashkortostan). For example, the plant produces TZA/KAMAZ concrete mixers (with a capacity of 5-12 $\mathrm{m}^{3}$ ), which are intended for transportation to laying sites or concrete-feeding devices (concrete pumps and stationary concrete pumps). The TZA concrete mixer truck effectively combines transportation to the installation site at the construction site and the supply of concrete mix (up to $50 \mathrm{~m}^{3} / \mathrm{h}$ ) to the required height $-28.4 \mathrm{~m}$, which allows you to maintain optimal homogeneity of the concrete nanocomposition of $3 \mathrm{D}$-additive printing during transportation and pumping.

\section{CONCLUSION}

Technological equipment management for 3D additive printing of building nanocomposites reduces energy costs by $26-29 \%$, and at the same time reduces the level of vibration. The advantages of additive 3D-printing technologies in the construction of buildings and structures are as follows: digital robotization of the construction process, time reduction from design to completion by $8-11$ times, etc. The optimal choice for transporting the nanoconcrete mixture for $3 \mathrm{D}$ additive printing of building nanocomposites at distances from 4 to $6 \mathrm{~km}$ is the concrete mixer trucks with a volume of $6-8 \mathrm{~m}^{3}$.

\section{REFERENCES}

1. Slavcheva G.S., Artamonova O.V. The control of rheological behaviour for 3D-printable building mixtures: experimental evaluation of «nano» tools prospects. Nanotechnologies in Construction. 2019;11(3):325-334. Available from: doi: 10.15828/2075-8545-2019-11-3-325-334.

2. Kolesnikov A.G. Modernization of the construction of the extruder of a construction 3D-printer and the selection of compositions for it. Urbanistics. 2019;2:64-70. Available from: doi: 10.7256/2310-8673.2019.2.29597. 
3. Slavcheva G.S., Akulova I.I., Vernigora I.V. Concept and effectiveness of 3D printing for urban environment design. Housing Construction. 2020;3:49-55. Available from: doi: 10.31659/0044-4472-2020-3-49-55. (In Russian).

4. Sergeyeva O.Yu. Additive technologies and 3D modeling. Nanotechnologies in Construction. 2018;10(4):142158. Available from: doi: 10.15828/2075-8545-2018-10-4-142-158.

5. Khalikov R.M., Ivanova O.V., Korotkova L.N., Sinitsin D.A. Supramolecular impact mechanism of polycarboxylate superplasticizers on controlled hardening building nanocomposites. Nanotechnologies in Construction. 2020;12(5):250-255. Available from: doi: 10.15828/2075-8545-2020-12-5-250-255.

6. Chernishov E.M., Artamonova O.V., Slavcheva G.S. Nanomodification of cement-based composites in the technological life cycle. Nanotechnologies in Construction. 2020;12(3):130-139. Available from: doi: 10.15828/20758545-2020-12-3-130-139.

7. Ivanov L.A., Xu L.D., Bokova E.S. et al. Nanotechnologies: are view of inventions and utility models. Part V. Nanotechnologies in Construction. 2020;12(6):331-338. Available from: doi: 10.15828/2075- 8545-2020-12-6-331-338.

8. Perkins I., Skitmore M. Three-dimensional printing in construction industry: A review. International Journal of Construction Management. 2015;15(1):1-9.

9. Le T.T., Austin S.A., Lim S. et al. Mix design and fresh properties for high-performance printing concrete. Materials and Structures. 2012;45(8):1221-1232.

10. Asprone D., Auricchio F., Menna C. et al. 3D printing of reinforced concrete elements: Technology and design approach. Construction and Building Materials. 2018;165:218-231. Available from: doi: 10.1016/j.conbuildmat. 2018.01.018.

11. Komarinsky M.V., Chervova N.A. Transport of concrete mix in the construction of unique buildings and structures. Construction of Unique Buildings and Structures. 2015;1(28):6-31.

12. Ivanova O.V., Korotkova L.N., Khalikov R.M. Optimized control of the functioning of electrical equipment in 3D printing. In: Prospects for the development of processing technologies and equipment in mechanical engineering: Collection of articles of the 6th All-Russian Conf. Kursk: SWSU; 2021. p. 88-91.

13. Egorova N.V., Ivanova N.K., Komkov V.G. Constructions of concrete pumps. Scientific notes TOGU. 2018;9(2): 1052-1057.

14. Ivanova O.V., Korotkova L.N., Fattakhov M. M. et al. Reliable quality management of electrical equipment functioning in 3D additive technologies. Electrotechnical and Information Complexes and Systems. 2020;16(3):43-49.

15. Vazdaev K.V., Ivanova O.V., Khalikov R.M. et al. Quality management of the functioning of the technological water supply line with the use of modern sensors. Construction and Technogenic Safety. 2018;13(65):127-132.

16. Ivanova O.V., Khalikov R.M., Korotkova L.N. Effective management of electrotechnical equipment of technological scheme of production of qualitative water. Electrotechnical and Information Complexes and Systems. 2018;14(2):21-27.

17. Khalikov R.M., Ivanova O.V. Technological schemes of solution of ecological problems of regional production of materials. Nauka-Rastudent.ru. 2014;3(03):10.

18. Pustovgar A.P., Adamtsevich A.O., Volkov A.A. Technology and organization of additive construction. Industrial and civil construction. 2018;9:12-20.

19. Pavlov A.P., Dvoryankin A.O. Ensuring the reliability and operability of 3D printers. Recovery. Modernization. 2020:8:20-25. Available from: doi: 10.31044/1684-2561-2020-0-8-20-25. (In Russian).

20. Luneva D.A., Kozhevnikova E.O., Kaloshina S.V. Application of 3D printing in construction and prospects of its development. Bulletin of the Perm National Research Polytechnic University. Construction and architecture. 2017;8(1):90-101.

21. Gusev B.V. Concrete with fillers of various dispersion and their nanomodification. Nanotechnologies in Construction. 2019;11(4):384-393. Available from: doi: 10.15828/2075-8545-2019-11-4-384-393.

22. Gusev B.V., Kudryavtseva V.D., Potapova V.A. Concretes with nanoadditive of fired recycled concrete. Nanotechnologies in Construction. 2020;12(5):245-249. Available from: doi: 10.15828/2075-8545-2020-12-5-245-249.

23. Sinitsin D.A., Khalikov R.M., Bulatov B.G. et al. Technological approaches to directed structure formation of construction nanocomposites with increased corrosion resistance. Nanotechnologies in Construction. 2019;11(2):153164. Available from: doi: 10.15828/2075-8545-2019-11-2-153-164.

24. Pudovkin A.N., Sinitsin D.A., Salov A.S. et al. Technological processes of concrete mix production. Equipment, mechanization, automation. Ufa: USPTU; 2019.

25. Strizhnev I.V., Frolov Yu.A., Kinev S.A. et al. Side fence. Russian Federation Patent 102944 U1. 2011-03-20.

26. Ivanova O.V. Dictionary of basic terms of quality management. Ufa: BashSU Publishing House; 2014.

27. Savelyeva N.A., Chernyshev A.N. Evaluation of construction products in the quality management system. Audit and financial analysis. 2008;3:312-318. 
28. Ivanova O.V. Certification and licensing in the field of transport systems. Ufa: USPTU; 2019.

29. Bedov A., Salov A., Gabitov A. CAD methods of structural solutions for reinforced concrete frame. IOP Conf. Ser.: Mater. Sci. Eng. 2018;365:052032.

30. Semin A.S., Vakhrushev S.I. Technical and economic comparison of variants of concrete mixers of various sizes. Modern technologies in construction. Theory and practice. 2018;2:445-454.

31. Frey V., Ruf B. Control device for concrete mixer truck. Russian Federation Patent 2467872 S2. 2012-11-27.

\section{INFORMATION ABOUT THE AUTHORS}

Olga V. Ivanova, Cand. Sci. (Eng.), Associate Professor at the "Technical Systems Control and Service" Department, Institute of Architecture and Civil Engineering, Ufa State Petroleum Technological University, Ufa, Russia; ORCID: https://orcid.org/0000-0002-8366-2004, e-mail: olgachemist@mail.ru

Rauf M. Khalikov, Cand. Sci. (Chem.), Associate Professor at the "Highways and Structural Engineering” Department, Institute of Architecture and Civil Engineering, Ufa State Petroleum Technological University, Ufa, Russia; ORCID: https://orcid. org/0000-0001-7584-5516, e-mail: rauf_khalikov@mail.ru

Alexander S. Salov, Cand. Sci. (Eng.), Associate Professor at the "Highways and Structural Engineering” Department, Institute of Architecture and Civil Engineering, Ufa State Petroleum Technological University, Ufa, Russia; e-mail: salov@list.ru

Malik Kh. Nizamutdinov, Cand. Sci. (Eng.), Associate Professor at the "Technical Systems Control and Service" Department, Institute of Architecture and Civil Engineering, Ufa State Petroleum Technological University, Ufa, Russia; e-mail: nizmal@mail.ru

Vyacheslav V. Zinnatullin, senior lecturer at the "Technical Systems Control and Service" Department, Institute of Architecture and Civil Engineering, Ufa State Petroleum Technological University, Ufa, Russia; e-mail: slawa915@yandex.ru

\section{Authors declare the absence of any competing interests.}

Received: 09.03.2021.

Revised: 28.03.2021.

Accepted: 31.03.2021. 